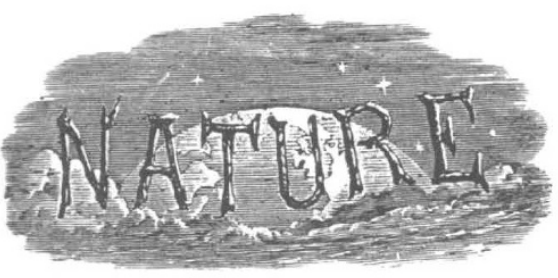

SATURDAY, AUGUST 22, I93I.

\begin{tabular}{lr}
\hline & \\
\hline & \\
\hline & \\
\hline
\end{tabular}

Editorial and Publishing Offices:

MACMILLAN \& CO., LTD.,

ST. MARTIN'S STREET, LONDON, W.C. 2.

Editorial communications should be addressed to the Editor.

Advertisements and business letters to the Publishers.

Telephone Number: GERRARD 8830.

Telegraphic Address: PHUSIS, WESTRAND, LONDON.

\section{Scientific Aspects of the Unemployment Problem.}

$\mathrm{E}$

VEN more perhaps than Dr. Miall's " History of Chemical Chemistry", the programme of the recent jubilee meetings of the Society of Chemical Industry illustrates the remarkable extent to which, during the last fifty years, the science of chemistry has penetrated and transformed almost every section of industry, if notindeed of the public services. Examples are to be found in the scientific papers presented at the meetings, which covered not only chemical industry generally and such special sections of it as the dyestuff industry, but also a discussion on fuel subjects which embraced questions of fundamental importance to society in general as well to industry. Striking evidence of the widespread impact of science upon industry is to be found in the technical visits paid by members of the Society. These covered such diverse industries as wallpaper manufacture, the research laboratories of the General Electric Co., Ltd.--which provide an outstanding example of an industry created and continually expanded by the application of scientific research-dry cleaning, fine chemicals and drugs, gas, coke and tar, brewing, agriculture, foodstuffs, fuel research, the protection of metals against corrosion; while visits to the National Physical Laboratory and the Chemical Research Laboratory demonstrated the vital importance of scientific research in national life.

It is against such a background that the true bearing of Sir Harry McGowan's presidential address to the Society of Chemical Industry, discussing the reaction of scientific and technical progress on the finance and economy of the modern State, is perceived. Scientific discoveries and their application in industry have dislocated the major balance between industrial and agricultural production and have threatened the whole social, financial, and political structure of our civilisation. Sir Harry McGowan uttered no idle warning when he hinted at the possibility of our common civilisation perishing through our inability to control the forces which applied science primarily has created. Under the influence of science, not only industry but also accepted views of trade and competition are changing their value, and policies such as free trade or protection acquire a new significance.

Sir Harry McGowan urged that the policy of industrial co-operation which has developed notably in chemical industry under such forces should be extended into the more difficult field of international co-operation-as indeed has already been done in 
some few branches of industry, though with what success it is difficult as yet to say. As an aid to such control or development, Sir Harry McGowan visualised a Minister of State devoted to the task of promoting the co-ordinated reorganisation of all our industries, and beyond this an international chemical council to provide chemical industry with a world-wide range. The effective rationalisation thus secured would stabilise development and coordinate or expedite research.

To turn from the picture of industrial and international co-operation thus eloquently painted to the efforts of Parliament during the past session to cope with unemployment and the general industrial situation is to realise how far from commensurate with the rapidity of technological or scientific advance in the last fifty years is the influence which representatives of science or of scientific industry are able to exert on the direction of public affairs. Examples of this have already been the subject of comment in these columns. Thus, the Royal Commission on Transport in its final report made certain recommendations regarding both road and rail transport which were intended to assist the general economic development of the nation. Neither in respect of the electrification of suburban services nor in the diversion of heavy goods traffic from road to rail have any adequate steps been taken to give effect to the recommendations of the Commission, although both these recommendations should encourage employment and the recovery of the railways from their difficult position. In the absence of a more scientific policy, it is still common for a heavy goods lorry to do damage to a road in a few hours amounting to several times the combined value of the lorry and its load.

A similar hiatus between knowledge and action exists in the fuel question. A really scientific consideration of the coal and fuel industries would alleviate considerably the difficulties in which the coal industry finds itself. Lack of courage, however, remains the characteristic Government attitude in 1931 as in 1926, and not even the growing seriousness of atmospheric pollution or the intensity of the unemployment situation has driven Parliament to examine the utilisation of our coal resources in the form of smokeless fuel or oil fuel as a possible economic policy worthy of development. The fuel problem and the competition between raw coal, gas, and electricity is still allowed to develop along haphazard lines, without any attempt to plan and enact a scientific and economic national policy. To this position no contrast could be more startling than the discussion on fuel subjects at the recent jubilee meetings of the Society of Chemical Industry, which was planned to elucidate definite answers to such questions as the probable effect upon the amount of coal raised, of the increasing use of oil, of the future development of the gas and electrical industries, of a large development of low temperature carbonisation, or of a general improvement of the standard of living. Only upon the considered answers to such questions can an adequate fuel policy be based, yet here again it is science and industry and not Parliament which is conducting the inquiry. The conference indeed took a sombre view of the prospects of any increased demand for coal, Dr. Lessing considering that a decrease in consumption is more probable; and even in the development of the hydrogenation process, prospects of an increased output of raw coal are not bright. Although international agreements might secure more lucrative prices, they are unlikely to affect the tonnage of coal raised. Lieut. Commander Kenworthy's suggestion that scientific workers, economists, and business men should set up a representative body to examine the economic side of the coal problem was itself a confession that Parliament is not the instrument which will put coal mining on its feet. Essentially the plea was an admission that the fuel problem demands scientific treatment as an organic unit by the best brains of the country, unfettered by political ties.

When we pass to the direct contribution of the recent parliamentary session to the relief of unemployment, our present system of government shows to no greater advantage. For a sanctioned expenditure of up to $£ 173,000,000$ on emergency work for the relief of unemployment, work has been found for an additional 200,000 only, not allowing for any possible effects of discontinuing the safeguarding on gloves, lace, and cutlery. Such is the outcome not merely of this large expenditure of money but also of Parliament's endeavours to induce reorganisation of the coal, cotton, and iron and steel industries, Acts on housing, land drainage, and transport, and the expenditure of large sums on electrification, road improvement, and afforestation. There can indeed be no fairer comment on the situation than the recommendation of the Macmillan report that we should attack the task of capital development in England in a much more systematic and far. sighted manner than hitherto. An era of conscious and deliberate management must succeed the era of undirected natural evolution. 
It is, of course, alleged by some that science itself causes unemployment, and that the increased production made possible by the mechanisation of industry under the influence of science is mainly responsible for our present difficulties. Superficial support may be found for such a view, but apart from the unescapable fact that industries such as the wireless industry--in which there is no unemployment-the electrical industry in all its branches, the automobile industry, the chemical industries, and aviation, which provide employment for millions of workers for whom otherwise there could be no industrial occupation, are the direct outcome of creative science and its application, the evidence of such industrial leaders as Mr. Henry Ford indicates that industrial leadership and continuous improvement in efficiency lead to industrial expansion and increased employ. ment. The idea that there is only a limited amount of employment in the world has been revived in the present crisis, but remains a fallacy. The temporary unemployment due to displacement of workers during the genuine rationalisation of an industry, the permanent displacement of certain workers through the rise of a new industry such as the rayon industry, and the decline of the older textile industries, even though the final volume of employment is increased, tend to obscure the real issues, and the confusion is heightened by the failure of the industrialist either to foresee the problems and difficulties involved or to secure a minimum disturbance during the transition period.

The possibilities in the application of scientific method to the unemployment problem are indicated not only by the Macmillan report, which visualises a comprehensive re-building and replanning policy for our larger towns and industrial centres, the re-planning and re-fitting of stable industries, and the electrification of railway systems, but also by the International Labour Office in its proposals for practical action on unemployment in Europe, which were recently submitted to the Commission of Inquiry for European Union. Without elaborating a definite scheme, the memorandum outlines such ideas as a definitely planned international road system to meet the probable requirements of rapidly increasing motor traffic and to provide connexions between the special roads for motor traffic which are at present being constructed everywhere independently in the most advanced countries of Europe; the coordination of regional systems of navigable waterways; the international distribution of electric power; and the concerted and uniform substitution on all European continental railways of a suitable system of automatic coupling in place of the present screw couplings, which are annually responsible for many fatal accidents. Schemes of this type planned in advance as a definite programme would enable public works to be postponed from a boom period and carried out in a time of depression. They should thus be of direct value in reducing the incidence of unemployment as well as in encouraging the spirit of European co-operation on which the Macmillan report laid such stress.

Any such schemes of development will now have to be considered in the light of the report of the May Committee on National Expenditure, which is under consideration by the Cabinet. As we have already pointed out, this committee included no one familiar with scientific progress and development, and research departments have clearly been singled out for drastic economies. It is evident that the members of the committee still hold to the fallacy that research is a luxury because its results cannot always and immediately be translated into pounds sterling on an annual report or balance sheet.

The real difficulty to-day is that science has not even yet come to take its right place in the direction of both industry and national affairs. Broadly speaking, those industries in which science is associated with commercial and financial interests in direct administrative control are the industries which have proved most able to meet the present industrial depression. The comparative impotency of Parliament in the present industrial situation is largely due to its lack of inherent scientific and technical knowledge, as well as to the absence of such knowledge in those holding high administrative appointments in the Civil Service. No severer handicap has been imposed on Great Britain in the present crisis than the exclusion, often deliberate, of technical and scientific men of administrative ability from responsible administrative posts in industry or in Government service. Not until this defect is remedied in Parliament, as in Government service and industries generally, can we expect to see not merely effective and scientific reorganisation of our industries from the point of view of the nation as a whole, but also the initiation of the task of wise international co-operation in a spirit of unselfishness and world service. Such reorganisation and international co-operation will open increasing opportunities for creative science, to which alone in the changing face of industry the worker can look for continued and adequate employment. 